\title{
ROMPENDO OS PADRÕES DE ALBINISMO
}

BREAKING ALBINISM PATTERNS

Andreza Cavalli *

\begin{abstract}
Resumo
Desde o início do século XXI, as pessoas com albinismo podem estar conquistando cada vez mais espaço no universo da moda e publicidade, assim como outras minorias, reconhecidas como essa tal diversidade. Tal fato pode ser percebido e recebido de forma positiva pela comunidade de pessoas com albinismo no que diz respeito à inclusão e ao fortalecimento do sentimento de pertencimento a esses espaços. Mas será que o chamado "cliente', ou seja, aquele quem contrata a propaganda ou mesmo o estilista, realmente compreendem e reconhecem a natureza do albinismo, ou eles têm em mente um padrão pré-estabelecido do estereótipo da pessoa com albinismo? Isso é impossível de se afirmar na sua totalidade. O ensaio visual aqui apresentado busca ilustrar diversas formas de olhar para o albinismo, com o propósito de "romper os padrões de albinismo", que talvez possam ainda habitar no inconsciente da moda e publicidade, especialmente no que diz respeito ao estereótipo.
\end{abstract}

Palavras-chave: albinismo; diversidade no albinismo; albinismo na moda; albinismo na publicidade.

\begin{abstract}
Since the beginning of the 21st century, people with albinism (PWA) may be gaining more and more space in the world of fashion and advertising, as well as other minorities; all recognized under the term diversity. This fact can be perceived and received positively by the community of people with albinism, with regard to inclusion and strengthening the feeling of belonging to these spaces. But does the so-called "client", that is, the one who hires the advertising or even the stylist, really understand and recognize the nature of albinism, or do they have in mind a pre-established stereotype of the person with albinism? This is impossible to affirm in its entirety. The visual essay presented here seeks to illustrate different ways of looking at albinism, with the objective of "breaking the patterns of albinism", which perhaps may still inhabit the unconscious of fashion and advertising, especially with regard to stereotype.
\end{abstract}

Keywords: albinism, diversity in albinism; PWA model; albinism in advertising.

\section{Introdução}

Com dez imagens de ensaios fotográficos realizados com pessoas com albinismo, com distintas características físicas, será possível ilustrar que ser pessoa com albinismo não implica somente em ter uma característica física específica, capaz de determinar um

\footnotetext{
* Graduada em Engenharia Elétrica pela Universidade Presbiteriana Mackenzie/Brasil e licenciada em Educação Física pela USP/Brasil. E-mail: entusiastaaguida@gmail.com.
} 
padrão de albinismo, mas sim que essa tal diversidade também é possível de ser observada através das distintas características físicas presentes em pessoas com albinismo, o que reforça a necessidade de desconexão dos padrões, oriundos de uma característica física entendida como "comum".

Características físicas que também são reflexo das distintas etnias existentes, da descendência, da miscigenação, que reforçam essa necessidade de se olhar para o albinismo para além da cor da pele, dos cabelos e da cor dos olhos.

\section{Foto 1 - Albnegro (Minas Gerais)}

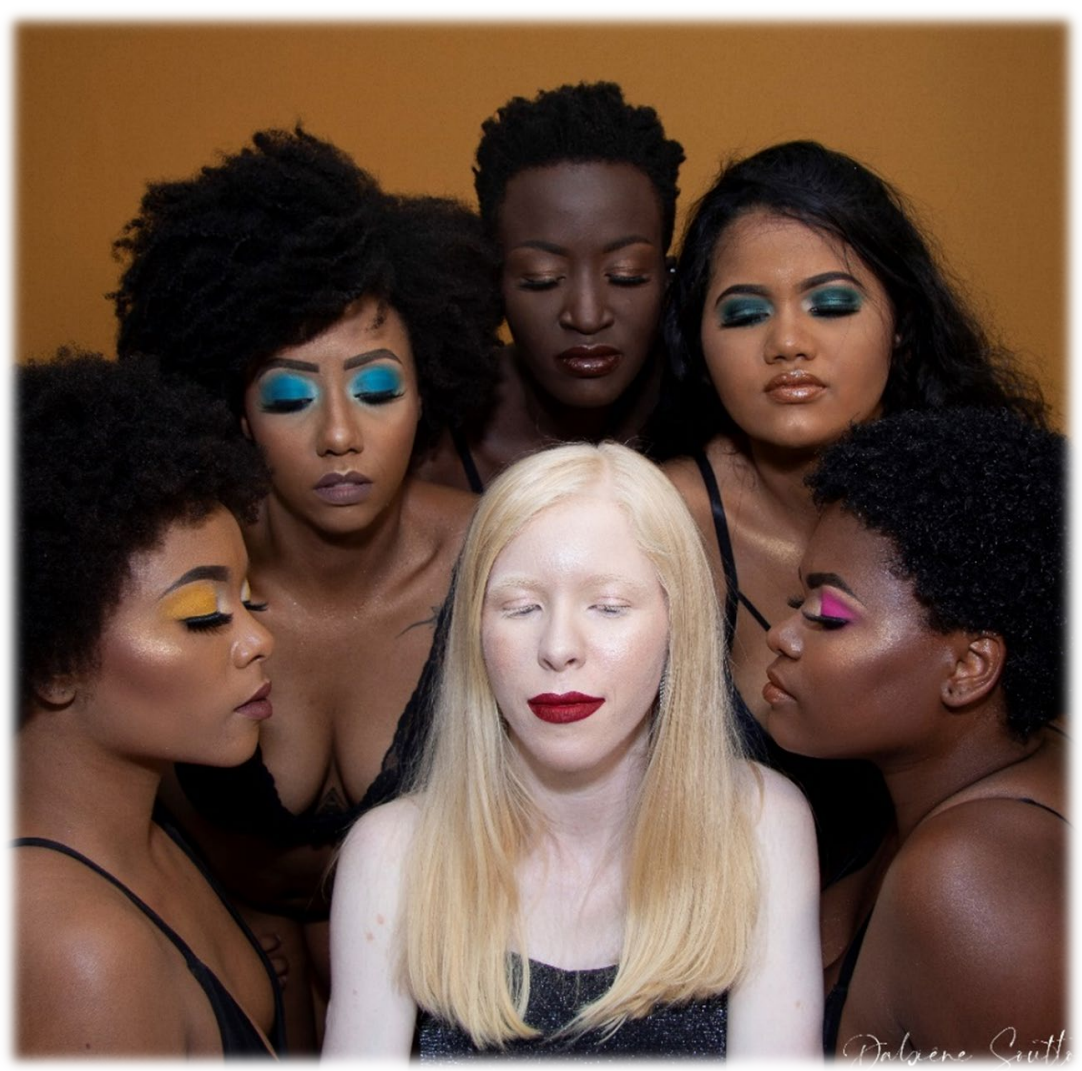

Essa tal "diversidade"

Essa tal "diversidade" Tá na moda Virou moda Hoje é realidade Tá no campo de visão Rica multiplicidade De cores, corpos e tons ${ }^{1}$

Modelos: Mari Silva (mulher com albinismo), Gabriela Santos, Victoria Lima, Ketlen Felix, Ellen Luiza, Pollyane | Maquiadoras: Maria Izabel Alves e Caroline Pereira Passos |Fotógrafa e idealizadora do projeto: Dabiêne Soutto

\footnotetext{
${ }^{1}$ Autora das poesias: Andreza Cavalli.
} 
Foto 2 - Ser tão branco (Bahia)

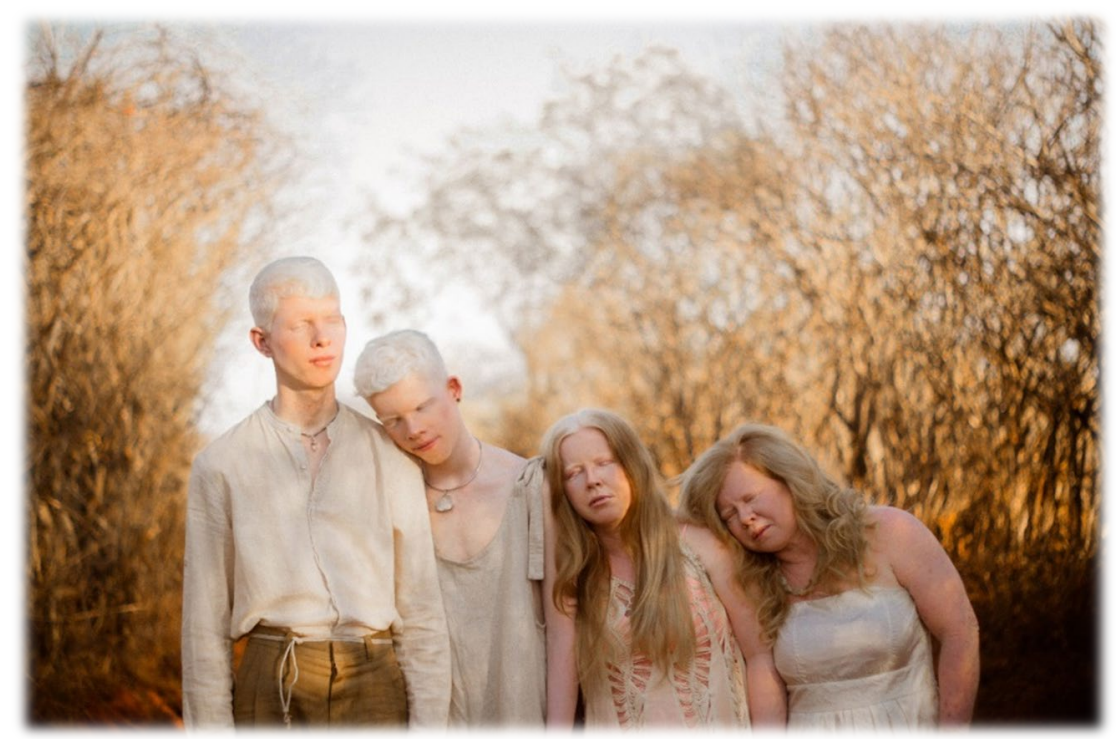

Essa tal "diversidade"

Ocupando a cidade

O campo e o sertão

Com representatividade

Trazendo reflexão

Chegou cheia de vontade

De romper com o padrão

A sua prioridade

Foi fazer revolução

Modelos: Gustavo Lima, Neide Marques, Rosana Marques, Tiago Lima | Equipe de produção e professores orientadores: João Anthônio e Laura Assis | Fotógrafo: João Anthônio - @jaoanthonio e Laura Assis - @lauliric_a

Foto 3 - Laiz (Rio de Janeiro)

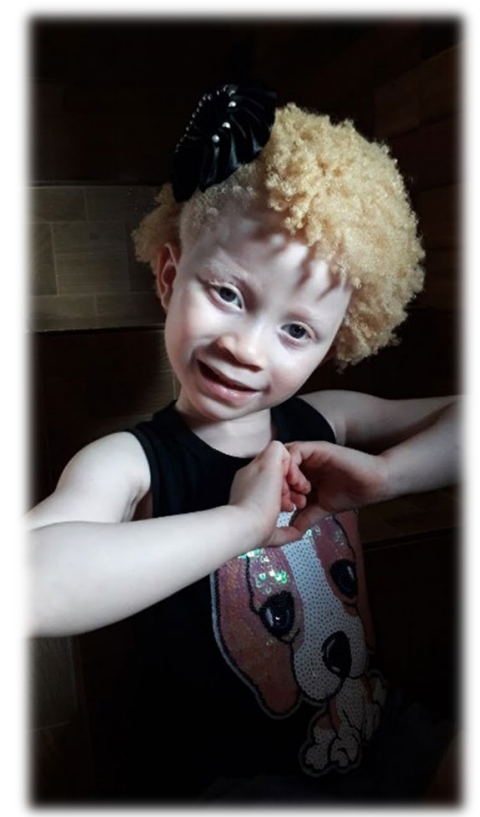

Essa tal "diversidade"

Saiu da invisibilidade

Com seu olhar de criança

Cheio de maturidade

E também de confiança

Que sua pluralidade

Voará longe

Até onde

Todo mundo alcança

Modelo: Laiz Paiva | Fotógrafa: Patrícia Paiva (mãe) 
Foto 4 - Zenaide Menezes (Pernambuco)

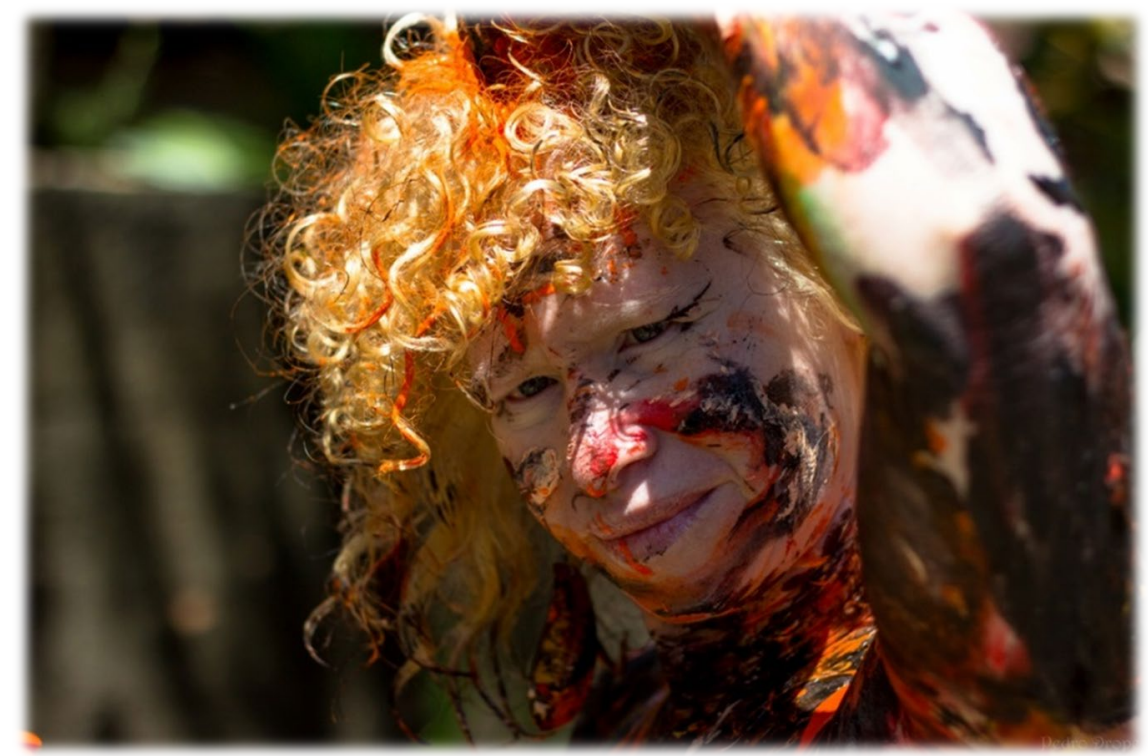

Essa tal "diversidade"

Deixou de ser ilusão

Agora é de verdade

Na moda

E publicidade

Jácausou transformação

Pois era necessidade

Promover a inclusão

Modelo: Zenaide Menezes | Fotógrafo: Pedro Drope

Foto 5 - Miguel (Minas Gerais)

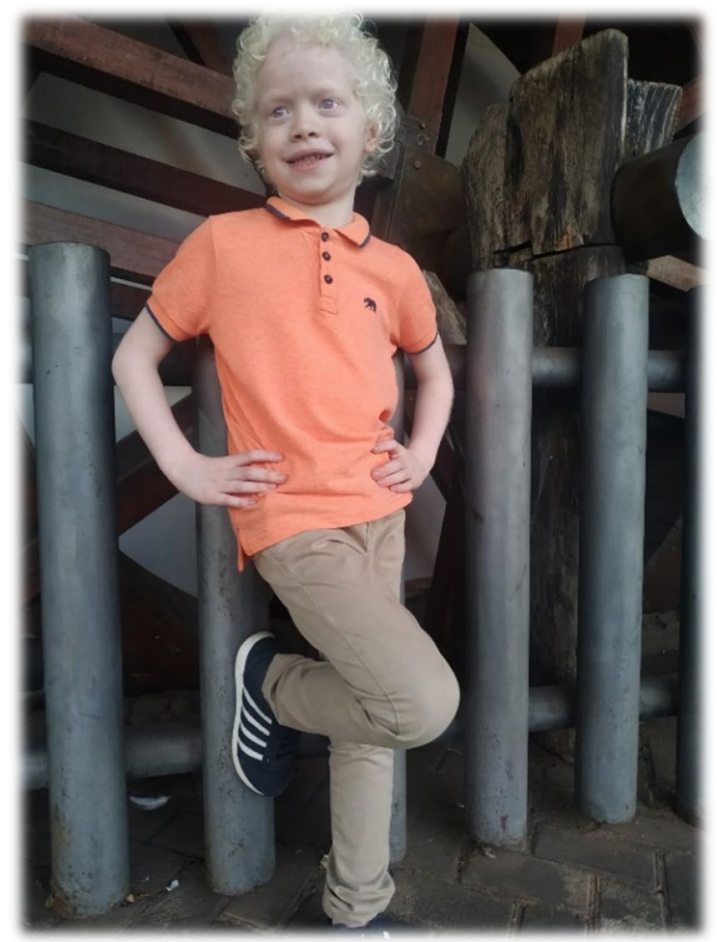

Essa tal "diversidade"

Num lugar antepassado

Vivia na exclusão

Pois parte de uma sociedade

Não queria abrir mão

De impor sua opinião

Determinando o padrão

Por meio da televisão

Modelo: Miguel Silva | Fotógrafa: Elaine Silva (mãe) 
Foto 6 - Dayane (São Paulo)

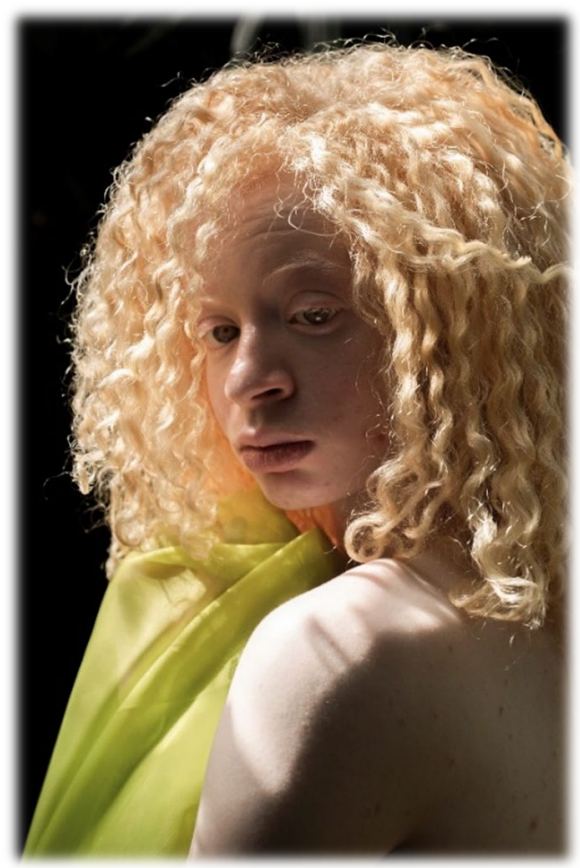

Essa tal "diversidade"

Trouxe a inquietação Sobre o que é normalidade

Nessa comunicação

Da publicidade e moda

Fez sua indagação

Viu oportunidade

De ter espaço na roda

Pra trazer ampliação

Dessa observação

Modelo: Dayane Galdino | Fotógrafa: Victoria LLo Ré

Foto 7 - Mara Lara (São Paulo)

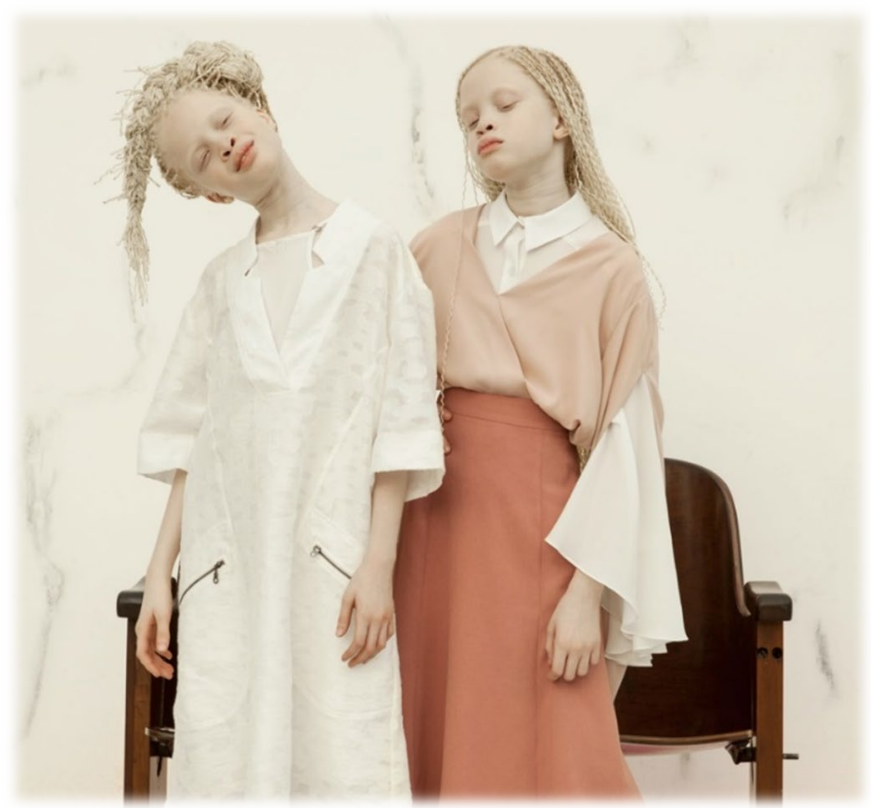

Essa tal "diversidade"

Pra bem dizer a verdade

Trouxe muita informação

Dúvida

Contradição

Será que é reconhecida

Na sua totalidade?

A resposta dada

É:

Possivelmente não

Será que existe um padrão?

Modelos: Mara Bawar e Lara Bawar | Fotógrafo: Vinicius Terranova 
Foto 8 - Isaac Arthur (São Paulo)

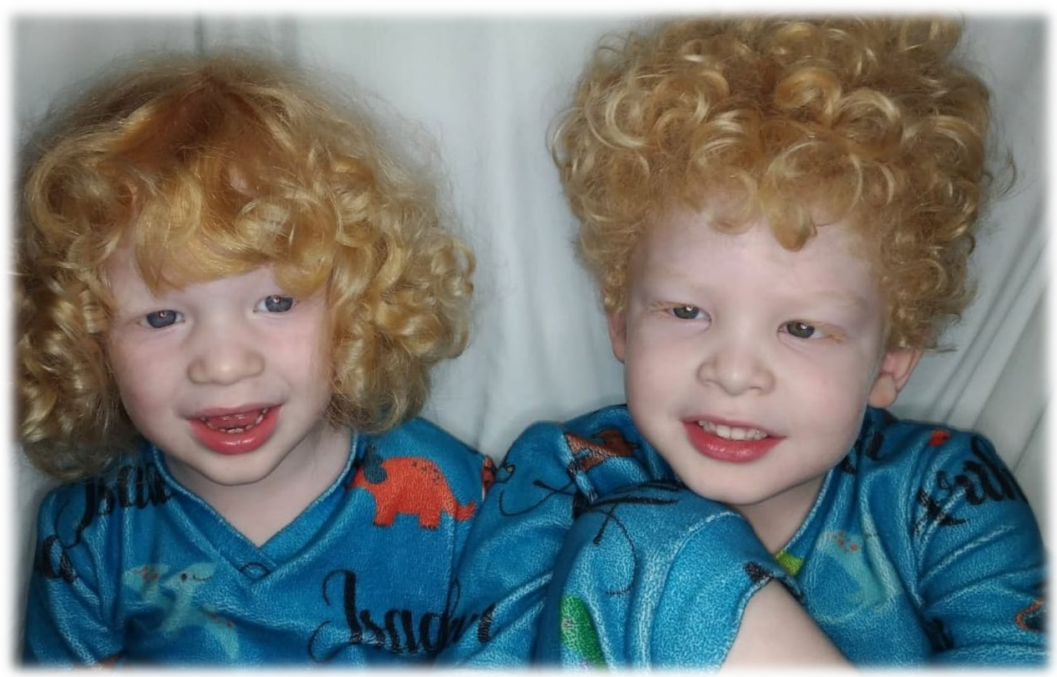

Essa tal "diversidade"

Nos seres com albinismo

Tem uma pluralidade

Que nem sempre está visível

Na moda e publicidade

E é algo tão incrível

Que merece visibilidade

Questão de

Oportunidade

Modelos: Isaac Silva e Arthur Silva | Fotógrafa: Vitória Silva (mãe)

Foto 9 - Naturalmente empoderada (São Paulo)

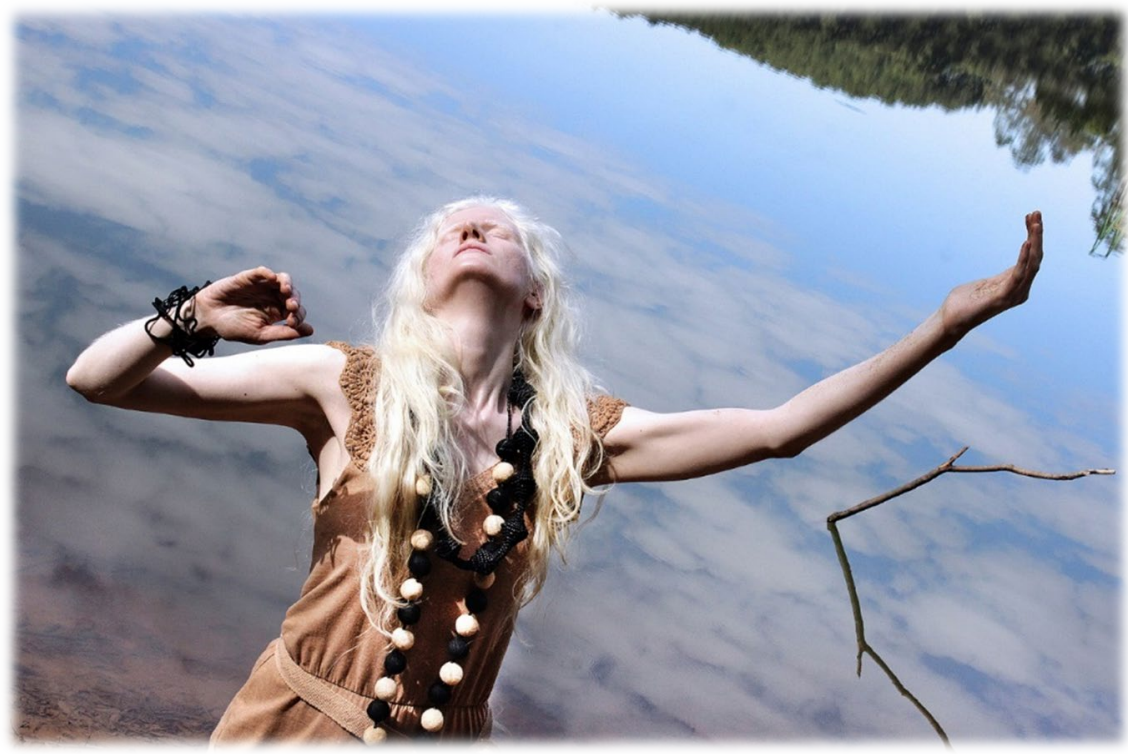

Essa tal "diversidade"

Dos seres comalbinismo

Traz uma afirmação

Pra toda sociedade

Porque na realidade

Elanão apenas representa

Falta de pigmentação

Modelo: Andreza Aguida | Fotógrafo: Rogério Ortiz | Figurino: Romero Souza 
Foto 10 - Laiz acompanhada (Rio de Janeiro)

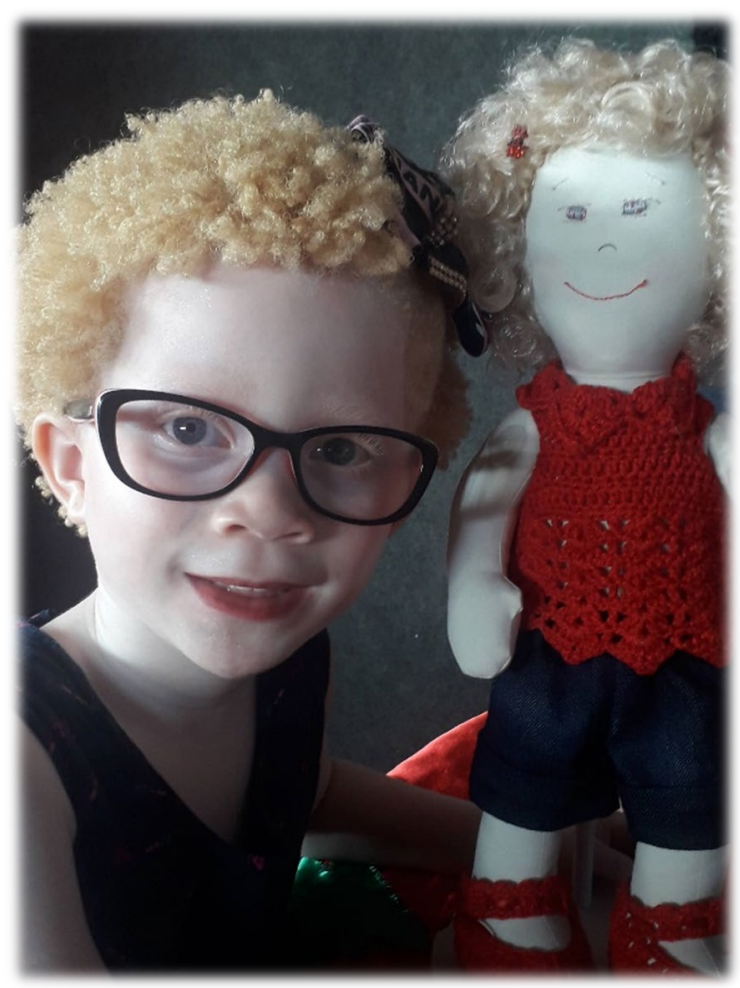

Essa tal "diversidade" Também pode estar presente Em qualquer sexo, gênero, etnia De uma população Características físicas diversas Extensa colorimetria Seu nome?

Diversidade com albinismo Visível! PRESENTE!

Modelo: Laiz Paiva | Fotógrafa: Patrícia Paiva (mãe)

Recebido em: 13/07/2021.

Aceito em: 07/09/2021. 